NBER WORKING PAPER SERIES

\title{
HOSPITAL COMPETITION, MANAGED CARE AND MORTALITY AFTER HOSPITALIZATION FOR MEDICAL CONDITIONS: EVIDENCE FROM THREE STATES
}

\author{
José J. Escarce \\ Arvind K. Jain \\ Jeannette Rogowski \\ Working Paper 12335 \\ http://www.nber.org/papers/w12335
}

\author{
NATIONAL BUREAU OF ECONOMIC RESEARCH \\ 1050 Massachusetts Avenue \\ Cambridge, MA 02138 \\ June 2006
}

This research was funded by grant number P01 HS10770-01 from the Agency for Healthcare Research and Quality. We would like to thank Randy Hirscher for expert programming assistance, Elaine Quiter for project management, and Kate Lee for administrative assistance. The views expressed herein are those of the author(s) and do not necessarily reflect the views of the National Bureau of Economic Research.

(C2006 by José J. Escarce, Arvind K. Jain and Jeannette Rogowski. All rights reserved. Short sections of text, not to exceed two paragraphs, may be quoted without explicit permission provided that full credit, including (C) notice, is given to the source. 
Hospital Competition, Managed Care and Mortality After Hospitalization for Medical Conditions: Evidence From Three States

José J. Escarce, Arvind K. Jain and Jeannette Rogowski

NBER Working Paper No. 12335

June 2006

JEL No. I1

\begin{abstract}
$\underline{\text { ABSTRACT }}$
This study assessed the effect of hospital competition and HMO penetration on mortality after hospitalization for six medical conditions in California, New York, and Wisconsin. We used linked hospital discharge and vital statistics data to study adults hospitalized for myocardial infarction, hip fracture, stroke, gastrointestinal hemorrhage, congestive heart failure, or diabetes. We estimated logistic regression models with death within 30 days of admission as the dependent variable and hospital competition, HMO penetration, and hospital and patient characteristics as explanatory variables. Higher hospital competition was associated with lower mortality in California and New York, but not Wisconsin. In addition, higher HMO penetration was associated with lower mortality in California, but higher mortality in New York. In the context of the study states' history with managed care, these findings suggest that hospitals in highly competitive markets compete on quality even in the absence of mature managed care markets. The findings also underscore the need to consider geographic effects in studies of market structure and hospital quality.
\end{abstract}

José J. Escarce

Division of General Internal Medicine

Health Services Research

911 Broxton Plaza

Box 951736

Los Angeles, CA 90024

escarce@rand.org

Jeannette Rogowski

Department of Health Systems and Policy

University of Medicine and Dentistry of

New Jersey (UMDNJ)

335 George Street, Suite 2200

New Brunswick, NJ 08903

and NBER

rogowsje@umdnj.edu 


\section{BACKGROUND}

Over the past two decades the structure of the U.S. health care industry has changed dramatically. In particular, the growth of managed care-especially health maintenance organizations (HMOs) — has led to the introduction of price competition among health care providers. Numerous studies have assessed the effects of changes in health care market structure on health care system performance. Studies of the hospital sector have confirmed that managed care has led to the intensification of price competition among hospitals (e.g., Feldman et al. 1990), and that price competition has resulted in lower rates of cost growth, lower prices and price-cost margins, and changes in the adoption and use of technology (e.g., Zwanziger and Melnick 1988; Robinson 1991; Gaskin and Hadley 1997; Melnick et al. 1992; Keeler, Melnick, and Zwanziger 1999; Baker and Phibbs 2002; Heidenreich et al. 2002; Bundorf et al. 2004). However, the effects of changes in hospital market structure on the quality of care provided by hospitals is less well understood. Only a handful of studies have addressed this issue and the findings have not been consistent.

The literature provides mixed evidence on the effects of hospital competition and managed care penetration on the quality of hospital care. In the earliest study, based on data from the early 1980s, Shortell and Hughes (1988) found that in-hospital mortality rates for 16 clinical conditions were higher in market areas with higher HMO penetration, but the number of competing hospitals in a market area was unassociated with mortality. More recently, Kessler and McClellan (2000) studied 1-year mortality for Medicare patients with acute myocardial infarction (AMI) in the 1980s and 1990s. They found that higher hospital competition was associated with decreased mortality, especially after 1990. HMO penetration was not associated 
with mortality, but the beneficial effects of hospital competition were stronger in high penetration market areas. By contrast, Mukamel, Zwanziger, and Tomaszewski (2001), using data from the 1990s, found no effects of hospital competition on 30-day mortality for Medicare patients with a variety of conditions, but higher HMO penetration was associated with lower mortality.

In a study based on hospital discharge data from 16 states in the 1990s, Sari (2002) examined the effects of hospital competition and HMO penetration on the rates of in-hospital mortality following common elective procedures, selected in-hospital complications, and inappropriate surgery. They found that higher hospital competition and higher HMO penetration were associated with lower rates of wound infections, iatrogenic complications, and inappropriate surgery. Shen (2003) found that faster growth in non-Medicare HMO penetration increased 7-day, 30-day, and 90-day mortality for Medicare patients with AMI, but did not affect longer-term mortality.

While the five studies reviewed in the preceding paragraphs considered competition globally, for all patients in a market, a recent study by Gowrisankaran and Town (2003) took a different approach by assuming that hospitals compete for HMO and Medicare patients separately. The investigators used data for Southern California in the early 1990s to study inhospital mortality for pneumonia and 30-day mortality for AMI. They found that competition for HMO patients was associated with lower mortality, whereas competition for Medicare patients was associated with higher mortality.

There are several potential reasons for the differences in findings across existing studies. Some of the differences may be attributable to differences in the time periods studied. The effects of hospital competition and managed care on hospital quality may have evolved over time 
as hospitals adapted to the new regime of price competition. Methodological differences across studies, including differences in measures of hospital quality or hospital competition, may contribute to differences in findings as well. For example, since hospitals in more competitive market areas and in areas with higher HMO penetration have shorter lengths of stay, and since shorter length of stay may shift deaths from the hospital to the period following discharge (Baker et al. 2002), use of in-hospital mortality (or complication rates) as the measure of quality may lead to bias toward finding that higher hospital competition and HMO penetration are associated with higher quality. The only studies that have been able to use mortality within a fixed time interval as the quality measure are those that focus on Medicare patients. Last, the effects of hospital competition and managed care may vary across geographic areas depending on the maturity of managed care markets or other factors. No study has directly addressed this possibility.

The goal of this study is to assess the effect of hospital competition and HMO penetration on hospital quality of care for six medical conditions, contrasting the findings for three states: California, New York, and Wisconsin. As shown in Figure 1, these states differ in their history and experience with HMOs. California, the prototypical example of a state with mature managed care markets, has had among the highest levels of HMO penetration since the early 1980s. HMO penetration in Wisconsin grew early, nearly equaling the level in California by 1985, but has since plateaued. New York had very low HMO penetration until about 1990, when penetration began to rise and eventually surpassed the level in Wisconsin. Our study is based on data for these three states between 1994 and 1999. 


\section{NEW CONTRIBUTION}

Our study contributes to the literature on hospital market structure and the quality of hospital care in three main ways. First, by linking hospital discharge and vital statistics data, we are able to use 30-day mortality as the quality measure while including all patients in the analysis, not just Medicare patients. Second, we use more recent data than prior studies. Finally, and most important, we examine the experience of three states that differ in their history with managed care and in the maturity of their managed care markets. Thus we assess the importance of considering state-specific effects when studying the effects of managed care penetration and hospital competition on hospital quality.

\section{CONCEPTUAL FRAMEWORK}

Hospital markets have evolved rapidly over the past two decades. In the 1970s, health insurance consisted of fee-for-service plans that allowed their insured members to use any hospital and paid for hospital care on a cost-reimbursement basis. Cost-based payment led hospitals to compete through the services, amenities, and convenience they offered rather than price. Under this form of nonprice competition, often called the "medical arms race," hospitals in more competitive markets had higher costs (Joskow 1980; Robinson and Luft 1985).

There are no studies of the impact of nonprice competition on the quality of hospital care. However, one study of hospital choice that used data from the early 1980s found that patients with a range of medical and surgical conditions were more likely to use hospitals having lower in-patient mortality, other things equal (Luft et al., 1989). This suggests that in the days of the "medical arms race" hospitals could compete for patients by offering higher quality of care. 
Changes in the types of health insurance plans and in hospital payment beginning in the early 1980 s led to dramatic changes in the nature of competition among hospitals. Rapid escalation in hospital costs led to the introduction of a prospective payment system for hospitals by Medicare, reducing incentives for hospitals to increase costs. More important, the emergence and rapid growth of managed care plans, especially HMOs, were enormously consequential. Managed care plans bargained with hospitals to obtain price discounts and selectively contracted with some of them to create networks of hospitals that would provide care to their insured members. Selective contracting by managed care plans introduced price competition into hospital markets and began to erode the "medical arms race" model of competition (e.g., Feldman et al. 1990). Of note, unique among the three study states, New York had an all-payer, prospective rate-setting system for hospitals until 1997. However, New York's system allowed HMOs to negotiate lower prices with hospitals beginning in 1988 (McDonough 1997).

Documented effects of price competition among hospitals include lower rates of hospital cost growth and lower rates of use of costly services and technologies (e.g., Zwanziger and Melnick 1988; Robinson 1991; Gaskin and Hadley 1997; Baker and Phibbs 2002; Heidenreich et al. 2002; Bundorf et al. 2004). Therefore, price competition, left unchecked, might be expected to adversely affect hospital quality of care by inducing hospitals to skimp on the resources used to care for patients. However, there is considerable indirect evidence that HMOs may have fostered quality competition among hospitals as well, by making quality a factor in their contracting decisions, at least in mature managed care markets like those in California.

The first line of indirect evidence comes from interviews and surveys of HMO executives in California, who report that they consider information on quality when choosing hospitals for contracts, even if the information is based on surrogate quality measures (Schulman et al. 1997; 
Rainwater and Romano 2003). Notably, Schulman at al. (1997) found that the use of quality information was infrequent in less mature managed care markets in Florida and Pennsylvania. The second line of evidence comes from studies that have assessed quality of care in hospitals used by large numbers of HMO patients compared with hospitals used by large numbers of patients with fee-for-service insurance. Escarce et al. (1999) found that HMO patients who received coronary artery bypass surgery were more likely than their peers with fee-for-service coverage to use low-mortality hospitals in California, but not in Florida. Erickson et al. (2000) found that patients in New York with managed care insurance were less likely than fee-forservice patients to use low-mortality hospitals for coronary artery bypass surgery. The final line of evidence comes from an econometric study of the determinants of contracts between HMOs and hospitals for bypass surgery, which found that HMOs are more likely to have contracts with hospitals that have low mortality rates, other things equal (Gaskin et al. 2002).

This discussion suggests that the effects of hospital competition and HMO penetration on the quality of hospital care are theoretically ambiguous. Although price competition might be expected to affect hospital quality adversely, quality competition would tend to offset this effect. Thus the net impact of hospital competition and HMO penetration on hospital quality is likely to depend on the relative strength of these counterbalancing influences. The discussion also suggests that the relative strength of price and quality competition may hinge on the maturity of managed care markets, with quality competition being strongest in the most mature markets. 


\section{DATA AND METHODS}

\section{Data and Study Sample}

The main source of data for this study consisted of linked hospital discharge and vital statistics data for three states: New York (1995-1999), Wisconsin (1994-1999) and California (1994-1999). (Linked data for 1994 were unavailable for New York.) The hospital discharge data contained detailed information on all discharges from short-term general hospitals in these states during the period in question, including admitting hospital; source of admission; patient age, sex, race/ethnicity, and zip code of residence; principal diagnosis and secondary diagnoses (up to 24 in California, 14 in New York, and 8 in Wisconsin); principal procedure secondary procedures (up to 24 in California, 14 in New York, and 5 in Wisconsin); and type of health insurance. The vital statistics data contained information on all deaths in these states during the period in question.

We identified adult residents of the study states who were admitted to hospitals in metropolitan areas from the community or from nursing homes for acute myocardial infarction (AMI), hip fracture (HIP), stroke (CVA), gastrointestinal hemorrhage (GIH), congestive heart failure (CHF), or diabetes mellitus (DM). We chose these six conditions because at least one study of geographic variation in hospital admission rates found that each was a low variation condition (e.g., Wennberg, McPherson, and Caper 1984; Gittlesohn and Powe 1995; McMahon, Wolf, and Tedeschi 1989; Chassin et al. 1986). In the framework developed by Wennberg (1987), low variation conditions tend to be those in which the criteria for hospitalizing patients are narrowly defined and for which there is a relatively high degree of professional consensus regarding the need for hospital admission. We wished to assess quality of care for conditions with these characteristics because hospital competition and HMO penetration may influence 
admission decisions for conditions in which hospital admission is discretionary. Thus, for discretionary conditions, hospital competition and HMO penetration are more likely to be correlated with unmeasured severity of illness, which may lead to biased estimates of their effects on health outcomes. Nonetheless, there are differences in the degree of consensus regarding the need for hospital admission even among the six study conditions. Whereas most clinicians agree that all patients with AMI, HIP, or CVA and most patients with GIH require hospitalization, admission decisions for CHF and DM are more discretionary. We excluded patients who lived in other states because vital statistics data are more likely to record deaths for state residents. We excluded admissions to hospitals in nonmetropolitan areas because we did not have data on HMO penetration.

We refined the study sample further in four ways. First, we excluded admissions for certain clinical variants of the study conditions to ensure more clinically homogenous samples or samples with a high likelihood of needing hospital admission. For example, we excluded HIP admissions where the fracture was due to primary or metastatic bone cancer or to major multiple trauma because these cases are very different from typical fractures, and we excluded GIH admissions where the hemorrhage was due to esophagitis or a Mallory-Weiss tear because these cases generally do not require admission.

Second, we included only first admissions in an "episode of care," defined as admissions where another admission for the same condition had not occurred within the preceding 90 days. For CHF, in particular, two or more admissions often occurred in close succession. Third, for California, we included only admissions that began between April 1, 1994 and November 30, 1999; for Wisconsin, we included admissions that began between April 1, 1994 and December 31, 1999; and for New York, we included admissions that began between April 1, 1995 and 
December 31, 1999. We excluded admissions in the first quarter of the first year of data for each state so we could identify first admissions in an episode of care. In addition, we excluded admissions in December 1999 for California so we could assess 30-day mortality (see below) without censoring, because the California vital statistics data only included deaths through 1999 . (The Wisconsin and New York vital statistics data included deaths through 2000.) Fourth, for each study condition, we excluded admissions to hospitals that had fewer than 25 admissions for that condition during the period of the study.

The final study sample consisted of $\mathrm{N}=1,321,531$ patients in California, $\mathrm{N}=876,704$ patients in New York, and N=200,872 patients in Wisconsin. These admissions were to 363 different hospitals in California, 190 in New York, and 61 in Wisconsin. The study hospitals were located in 25 different metropolitan areas in California, 13 in New York, and 13 in Wisconsin.

Other data sources used in the study were the American Hospital Association Annual Surveys of Hospitals, Medicare Cost Reports, and Medicare PPS Impact Files for 1994-1999.

\section{Empirical Analyses}

The measure of hospital quality in the study was 30-day mortality. We assessed the effect of hospital competition and HMO penetration on quality by estimating admission-level logistic regression models for each study condition within each state, using death within 30 days of admission as the dependent variable and hospital competition, HMO penetration, hospital characteristics ${ }^{1}$ and patient severity measures as explanatory variables.

\footnotetext{
${ }^{1}$ We used the characteristics of the hospital to which the patient was initially admitted even if the patient was subsequently transferred to a different hospital (e.g., Kessler and McClellan 2000; Gowrisankaran and Town 2003). Transfer rates were low for all study conditions except AMI (for California: AMI, 22.0 percent; HIP, 1.6. percent; CVA, 3.4 percent; GIH, 1.6 percent; CHF, 3.4 percent; and DM, 1.4 percent; for New York: AMI, 26.4 percent;
} 
The key explanatory variables in the models were hospital competition and HMO penetration. We assessed the degree of competition facing each hospital using the predicted 75 percent and 90 percent radii for the hospital, obtained from Gresenz, Rogowski, and Escarce (2004), to define the hospital's local market area. ${ }^{2}$ After identifying all the other hospitals in each hospital's local market area, we derived the following competition measures: (1) a competition index calculated as one minus the Herfindahl index based on bed shares, and (2) the square root of the number of hospitals. We used one minus the Herfindahl index based on the 90 percent radius in our main analyses, and conducted sensitivity analyses using the alternate measures. HMO penetration in each metropolitan area was measured as the fraction of the population enrolled in an HMO, obtained from the InterStudy Regional Market Analysis database for 1994-1999.

The hospital characteristics included in the models were teaching status, categorized as none, minor, or major based on the intern- and resident-to-bed ratio ${ }^{3}$ ownership, categorized as public (i.e., city or county-owned), private nonprofit, or private for-profit; ${ }^{4}$ and bed size, categorized as less than 100 beds, 100-199 beds, 200-399 beds, or 400 or more beds.

HIP, 3.1 percent; CVA, 2.6 percent; GIH, 1.0 percent; CHF, 3.7 percent; and DM, 0.9 percent; for Wisconsin: AMI, 12.3 percent; HIP, 2.0 percent; CVA, 3.2 percent; GIH, 1.2 percent; CHF, 2.6 percent; and DM, 1.2 percent). In effect, our approach holds the admitting hospital responsible for making transfers that would improve patient outcomes.

${ }^{2}$ Briefly, we used hospital discharge data for nine states in 1997 to determine, for each short-term general hospital in those states, the distance from the hospital to patient zip codes required to account for 75 percent and 90 percent of the admissions to the hospital. We then developed a regression model for the 75 and 90 percent radii as functions of hospital and market area characteristics, and we used the estimated coefficients to predict the radii for every metropolitan hospital in the U.S. (For details, see Gresenz, Rogowski, and Escarce [2004].)

${ }^{3}$ Teaching hospitals were those with any interns or residents, and major teaching hospitals were those with more than 0.25 interns and residents per bed. Data on interns and residents were obtained from Medicare Cost Reports.

${ }^{4}$ District hospitals in California are tax supported, but they resemble private nonprofit hospitals in most other ways. Because there are few district hospitals in metropolitan areas, we included them in the nonprofit category. All hospitals in Wisconsin were private nonprofits except for one public hospital, so we did not include ownership in the Wisconsin models. 
To control for differences in patient severity, we also included a variety of severity measures as covariates in the regression models, including patient age, sex, whether the patient was admitted from a nursing home, chronic comorbidities, and a set of condition-specific measures for each study condition. The chronic comorbidities used in the analyses were the conditions identified by Iezzoni et al. (1994) as conditions that are nearly always present prior to hospital admission; hence they are extremely unlikely to represent complications due to poor care. They included primary cancer with a poor prognosis, metastatic cancer, chronic pulmonary disease, coronary artery disease, congestive heart failure, peripheral vascular disease, severe chronic liver disease, diabetes mellitus with end-organ damage, chronic renal failure, nutritional deficiencies, dementia, and functional impairment. ${ }^{5}$ Examples of the condition-specific measures for AMI include indicators for the location of the infarction and for the presence of complete heart block; for CVA, indicators for hemorrhagic stroke and for different types of ischemic stroke; for GIH, indicators for the source of the bleeding, such as esophageal varices, different types of peptic ulcer with or without perforation or obstruction, arteriovenous malformations, and diverticulosis; and for DM, indicators for the type of diabetes (type 1 or type 2), for the presence of ketoacidosis and nonketotic coma, and for different end-organ complications. ${ }^{6}$ Finally, the models included indicator variables for year of admission.

\footnotetext{
${ }^{5}$ Elixhauser et al. (1998) developed a more comprehensive list of comorbidities. However, this list includes conditions, such as hypertension, paralysis, obesity, and uncomplicated diabetes, that have been found to be underreported in hospital discharge data, especially for patients who die (Romano and Mark 1994; Iezzoni et al. 1992; Iezzoni et al. 1994).

${ }^{6}$ To test the performance of these severity measures, we estimated logistic regression models for each study condition using death within 30 days as the dependent variable and the severity measures, alone, as explanatory variables. The c-statistics for these models ranged from 0.75 to 0.82 (with the exception of 0.66 to 0.69 for $\mathrm{CHF}$ ), indicating excellent discrimination. Additionally, comparisons of predicted and observed mortality across deciles of risk showed good calibration.
} 
Standard errors were corrected for clustering of admissions within hospitals using a Huber-White sandwich estimator. We converted the odds ratios from the logistic regression models to approximate relative risks using the method described by Zhang and Yu (1998).

\section{RESULTS}

\section{Descriptive Data}

Table 1 reports 30-day mortality for the six study conditions, by state. Mortality was lowest for DM and highest for CVA and AMI in every state. Comparing states, mortality rates were highest in Wisconsin, intermediate in California, and lowest in New York.

Patients in Wisconsin were slightly older than patients in the other states (data not shown). Thus $71.8 \%$ of Wisconsin patients were 65 years or older across all the study conditions, compared with $69.7 \%$ of patients in each of California and New York, and $18.8 \%$ of Wisconsin patients were 85 years or older, compared with $17.3 \%$ of California patients and $18.4 \%$ of New York patients. The percentage of women patients across the study conditions ranged from 51.3\% in California, to $51.7 \%$ in Wisconsin, to $54.0 \%$ in New York. Patients in Wisconsin averaged 1.02 chronic comorbidities, compared with 1.00 for patients in California and 0.98 for patients in New York. However, patients in California were more likely than those in Wisconsin or New York to be admitted to the hospital from a nursing home $(4.7 \%, 1.3 \%$, and $2.4 \%$, respectively).

Table 2 reports the characteristics of the hospitals that contributed admissions to the study sample in each state. The competition index (calculated as one minus the Herfindahl index) based on the 90 percent radius averaged 0.79 across hospitals in California, 0.72 in New York, and 0.68 in Wisconsin. On average, hospitals in California had 19.8 hospitals within their 
90 percent radius, compared with 28.0 hospitals for hospitals in New York and 8.0 hospitals for hospitals in Wisconsin. The competition measures based on the 75 percent radius exhibited similar patterns across the three states. The average HMO penetration in the metropolitan areas where the study hospitals were located was 0.43 in California, 0.34 in New York, and 0.32 in Wisconsin.

There were large differences across the study states in hospital ownership (Table 2). Hospitals in California were much more likely to be for-profit (27.0\%) than hospitals in New York (5.4\%), and Wisconsin had no for-profit hospitals. By contrast, hospitals in New York were more likely to be public (9.7\%) than hospitals in California (5.9\%) or Wisconsin (1.5\%). The teaching status of hospitals also differed across states. Only three in ten hospitals in California had teaching programs, compared with half in New York and Wisconsin. On the other hand, the proportion of hospitals categorized as major teaching hospitals was much larger in New York (28.5\%) than either California (7.6\%) or Wisconsin (5.3\%). The study states differed in the distribution of hospital size as well. Wisconsin had the highest fraction of small hospitals with fewer than 100 beds, while New York had the highest fraction of very large hospitals with 400 or more beds.

\section{Regression Results}

Tables 3a-3c report the findings of our main analyses regarding the effects of hospital competition, HMO penetration, and hospital characteristics on 30-day mortality for the study conditions in California, New York, and Wisconsin, respectively. We found that hospital competition was associated with lower mortality rates in California and New York. In California, five conditions had significantly lower mortality in hospitals that faced greater 
competition: HIP (relative risk $[R R]=0.75, p<0.01), \mathrm{CVA}(\mathrm{RR}=0.71, \mathrm{p}<0.001), \mathrm{GIH}(\mathrm{RR}=0.83$, $\mathrm{p}<0.05), \mathrm{CHF}(\mathrm{RR}=0.88, \mathrm{p}<0.10)$, and $\mathrm{DM}(\mathrm{RR}=0.82, \mathrm{p}<0.01)$. In New York, three conditions had significantly lower mortality in hospitals that faced more competition: AMI (RR=0.85, $\mathrm{p}<0.01)$, GIH $(\mathrm{RR}=0.86, \mathrm{p}<0.10)$, and $\mathrm{DM}(\mathrm{RR}=0.86, \mathrm{p}<0.10)$. The point estimates for the other conditions in both states were consistent with a protective effect of competition, but these estimates did not achieve statistical significance. ${ }^{7}$ Hospital competition was unassociated with mortality in Wisconsin.

The relative risks summarized in the preceding paragraph are consistent with clinically significant effects of hospital competition on mortality. For example, other things equal, a California hospital at the $10^{\text {th }}$ percentile of the competition index (one minus the Herfindahl index based on the 90 percent radius) had a 30-day mortality rate of $7.1 \%$ for HIP, compared with $6.2 \%$ in a hospital at the $90^{\text {th }}$ percentile of the index. The corresponding figures for other conditions were $18.4 \%$ and $15.6 \%$ for CVA, $6.2 \%$ and $5.6 \%$ for $\mathrm{GIH}, 9.0 \%$ and $8.4 \%$ for $\mathrm{CHF}$, and $3.9 \%$ and $3.2 \%$ for DM. Similarly, other things equal, a New York hospital at the $10^{\text {th }}$ percentile of the competition index had a 30-day mortality rate of $14.3 \%$ for AMI, compared with $12.2 \%$ in a hospital at the $90^{\text {th }}$ percentile of the index. The corresponding figures for other conditions were $6.6 \%$ and $5.7 \%$ for $\mathrm{GIH}$, and $3.2 \%$ and $2.7 \%$ for DM.

The effects of HMO penetration differed strikingly across the study states (Tables 3a-3c). In California, higher HMO penetration reduced mortality for GIH $(\mathrm{RR}=0.76, \mathrm{p}<0.05)$ and $\mathrm{CHF}$ $(\mathrm{RR}=0.78, \mathrm{p}<0.01)$, and the point estimates for most of the remaining conditions were consistent

\footnotetext{
${ }^{7}$ Kessler and McClellan (2000) and Gowrisankaran and Town (2003) have argued that measures of hospital competition based on patient flows may be endogenous to hospital quality, since hospitals with higher quality may draw patients from longer distances. We based our competition measures on predicted rather than observed radii, as described earlier, in order to avoid endogeneity, and we tested whether this strategy worked by estimating additional logistic models for 30-day mortality that included the hospital's predicted radius as an explanatory variable. The coefficient of the predicted radius was close to zero for all the study conditions in all states, and the coefficients of hospital competition did not change appreciably. Moreover, the statistical significance of the findings for competition was strengthened in California and only slightly weakened in New York.
} 
with a protective effect of HMO penetration, although these estimates did not achieve statistical significance. Similarly, in Wisconsin, higher HMO penetration reduced mortality for CHF ( $R R=0.66, p<0.01)$, and the point estimates for four of the five remaining conditions were consistent with a protective effect of HMO penetration. By contrast, in New York, higher HMO penetration was associated with higher mortality for HIP $(R R=1.54, p<0.001)$, CVA ( $R R=1.33$, $\mathrm{p}<0.01)$, GIH $(\mathrm{RR}=1.54, \mathrm{p}<0.01)$, and $\mathrm{CHF}(\mathrm{RR}=1.43, \mathrm{p}<0.01)$. Further, the point estimates for AMI and DM suggested a harmful effect of HMO penetration as well, but these estimates were not significant.

Because the estimated effects of hospital competition and HMO penetration were qualitatively similar for the six study conditions within each state (Tables 3a-3c), we estimated a model for each state where we pooled all the conditions and included interactions between condition and all the explanatory variables except competition and penetration. These analyses found significant protective effects of hospital competition in California $(\mathrm{OR}=0.80, \mathrm{p}<0.001)$ and New York $(\mathrm{OR}=0.89, \mathrm{p}<0.05)$, but not Wisconsin $(\mathrm{OR}=1.02, \mathrm{p}>0.05)$. The pooled analyses also found significant protective effects of $\mathrm{HMO}$ penetration in California $(\mathrm{OR}=0.86, \mathrm{p}<0.05)$ and Wisconsin $(\mathrm{O}=0.78, \mathrm{p}<0.05)$. However, in New York, higher HMO penetration was associated with higher mortality $(\mathrm{OR}=1.39, \mathrm{p}<0.001)$.

In addition, to assess whether the protective effect of hospital competition was greater in metropolitan areas with high HMO penetration, we estimated models where we again pooled all the study conditions but this time included an interaction between hospital competition and an indicator variable for metropolitan areas in the top half of the distribution of HMO penetration for each state. These analyses found a significant protective effect of hospital competition in both high and low penetration metropolitan areas in California, but the protective effect of 
competition was greater in high penetration areas $(\mathrm{RR}=0.81, \mathrm{p}<0.001$, in high penetration areas; $\mathrm{RR}=0.91, \mathrm{p}<0.10$, in low penetration areas; $\mathrm{p}<0.001$ for test of difference in odds ratios). The protective effect of hospital competition did not vary by HMO penetration in New York.

Other hospital characteristics were also associated with mortality for medical conditions (Tables 3a-3c), although the precise findings varied across the study states. Public hospitals in California had higher mortality than private nonprofit hospitals for AMI and lower mortality for CHF and DM, while public hospitals in New York had higher mortality for CVA. For-profit hospitals in California had higher mortality for AMI and lower mortality for CVA, CHF and DM, whereas for-profit hospitals in New York had lower mortality for HIP and CVA. In California, major teaching hospitals had higher mortality than non-teaching hospitals for CVA, GIH, and DM. By contrast, major teaching hospitals in New York had lower mortality than nonteaching hospitals for CVA, CHF, and DM, and major teaching hospitals in Wisconsin had lower mortality for DM. In California, large hospitals of 400 beds or more tended to have lower mortality than small hospitals with fewer than 100 beds. Large hospitals in New York had higher mortality than small hospitals for GIH and CHF, whereas in Wisconsin the effect of hospital size on mortality was mixed.

\section{Alternate Measures of Hospital Competition}

We explored the robustness of our findings for hospital competition using three alternate competition measures: the competition index based on the 75 radius and the square root of the number of hospitals based on both the 90 percent and 75 percent radii. As shown in Table 4, the finding of protective effects of hospital competition in California and New York was robust. In California, AMI was the only study condition for which higher competition did not reduce 
mortality. In New York, every study condition exhibited a protective effect of hospital competition for at least one competition measure, although within condition the level of statistical significance varied across measures. We found no evidence that hospital competition affected mortality in Wisconsin irrespective of the competition measure used. Our findings regarding the effects of $\mathrm{HMO}$ penetration on mortality did not change as we varied the measure of hospital competition (data not shown).

\section{Effect of Hospital Competition on Medicare Versus Non-Medicare Patients}

To assess whether the effect of hospital competition mortality differed for Medicare and non-Medicare patients (Gowrisankaran and Town, 2003), we estimated models for 30-day mortality that included the appropriate interaction terms. In California, the effect of competition differed only for AMI. Higher competition reduced mortality for non-Medicare patients with AMI $(\mathrm{RR}=0.89, \mathrm{p}<0.10)$, but not for Medicare patients. In New York, the effect of competition differed for four study conditions. Thus higher competition reduced mortality for non-Medicare patients with HIP $(R R=0.79, p<0.05)$, CVA $(R R=0.87, p<0.05), C H F(R R=0.88, p<0.10)$, and $\mathrm{DM}(\mathrm{RR}=0.80, \mathrm{p}<0.05)$, but not for Medicare patients with those conditions. For all other study conditions, higher competition had the same effect (or lack thereof) on both Medicare and nonMedicare patients. In no case did higher competition lead to higher mortality for Medicare patients.

\section{Additional Sensitivity Analyses}

We conducted additional sensitivity analyses to further assess the robustness of our results. First, hospital discharge data have been criticized for lacking the clinical detail necessary 
to capture illness severity adequately enough to assess hospital quality of care (e.g., Pine et al. 1997; Hannan et al. 1992). Therefore, we reestimated the models in our main analyses including an indicator for uninsured patients and an indicator for patients with insurance coverage from Medicaid or an indigent program under the rationale that these categories may capture unobserved dimensions of health status (e.g., Parkerson et al. 2005; Hadley 2003). The findings for hospital competition and HMO penetration in Tables 3a-3c were unchanged.

Second, due to the limited number of metropolitan areas in each study state, and because we were concerned that HMO penetration could be endogenous to hospital quality, we estimated models for 30-day mortality where we replaced the HMO penetration variable with metropolitanarea fixed effects. The findings for hospital competition were unchanged.

Third, because the New York City metropolitan area accounted for a large share of hospital admissions in the state of New York (one-third to two-fifths across conditions), and because some observers believe that the hospital market in New York City is atypical (Salit, Fass, and Nowak 2002), we repeated the analyses for New York excluding admissions to hospitals in New York City. The findings for hospital competition and HMO penetration were again unchanged.

Fourth, because New York did not fully abolish hospital rate-setting until 1997, we estimated models to test for differences in the effects of hospital competition and HMO penetration between 1995-1996 and 1997-1999. We did not find appreciable differences.

Finally, we estimated models with 90-day and 180-day mortality, rather than 30-day mortality, as the outcome. As Table 5 shows, the effects of hospital competition and HMO penetration on 90-day and 180-day mortality were similar to their effects on 30-day mortality, 
although the effects of competition were slightly attenuated in the analyses of 180-day mortality in California.

\section{DISCUSSION}

This study examined the effects of hospital competition and HMO penetration on the quality of hospital care for six medical conditions in California, New York, and Wisconsin. We found that hospitals in California and New York that faced a higher degree of competition generally had lower mortality rates within 30 days of hospital admission. Specifically, higher hospital competition led to lower mortality for five of the six study conditions in California and all six conditions in New York, although significance levels varied depending on the competition measure used. Analyses where we pooled the six study conditions also found protective effects of competition in California and New York. By contrast, hospital competition was unassociated with mortality in Wisconsin. Our findings regarding hospital competition were robust to a wide range of sensitivity analyses in which we employed alternate measures of hospital competition and varied the explanatory variables in the regression models. Similarly, analyses using 90-day or 180-day mortality as the outcome, rather than 30-day mortality, found beneficial effects of hospital competition in California and New York but not Wisconsin. In contrast to Gowrisankaran and Town (2003), we did not find that higher competition was associated with higher mortality for Medicare patients.

The study also found that higher HMO penetration was associated with lower mortality for gastrointestinal hemorrhage and congestive heart failure in California and for congestive heart failure in Wisconsin, and the analyses where we pooled the six study conditions found a 
beneficial effect of higher HMO penetration in California and Wisconsin as well. Moreover, when we included an interaction between hospital competition and HMO penetration in the regression models, we found that the protective effect of competition in California was stronger in metropolitan areas with high penetration. By contrast, in New York higher HMO penetration was associated with a substantial increase in mortality for four of the six study conditions and in the pooled analyses. We interpret our results for HMO penetration with caution due to the fact that penetration was measured at the level of metropolitan areas and each study state only had between 13 and 25 metropolitan areas. The small numbers of observations on HMO penetration, especially in New York and Wisconsin, coupled with the concern that HMO penetration could be endogenous to hospital quality, argue for regarding these results as suggestive rather than conclusive. Nonetheless, the difference across states in the findings for penetration is striking.

The results of this study are consistent with the thesis that hospitals competed on "true" quality of care-i.e., processes and outcomes of care—rather than just on price or amenities in California and New York, but not in Wisconsin. This observation raises two questions. First, what is the source of the divergent results for California and New York, on one hand, compared with Wisconsin, on the other? Although we cannot be certain, one possibility is that the effects of hospital competition on quality of care emerge only at high levels of competition. As shown in Table 2, hospitals in Wisconsin typically competed with many fewer hospitals than hospitals in either California or New York.

Second, and more important, do our results regarding the effects of hospital competition on hospital quality have anything to do with managed care? Our finding that in California hospital competition had a stronger beneficial effect on mortality in metropolitan areas with high HMO penetration suggests that HMOs in that state fostered quality competition among hospitals 
and that they were at least partly responsible for the competition effects on quality that we found. This interpretation is consistent with what is known about the maturity of managed care markets in California and with the indirect evidence, reviewed earlier, that HMOs in California have made hospital quality a factor in their contracting decisions. It is also consistent with our finding that higher HMO penetration, per se, was associated with lower mortality in California. A substantial presence in a market area of HMOs that take quality into account in contracting and that induce hospitals to compete on quality would be expected to lead to overall improvements in the quality of care in the area.

On the other hand, our finding that in New York the beneficial effect of hospital competition on mortality was the same in high and low HMO penetration areas, coupled with the finding that higher HMO penetration in a metropolitan area was associated with higher mortality, suggests that HMOs in New York may not have played a prominent role in promoting quality competition among hospitals. This interpretation is consistent with the observation that HMOs in New York did not begin to grow rapidly until the 1990s, and that hospital markets were not fully deregulated until 1997. It is also consistent with Erickson et al.'s (2000) finding that managed care patients in New York were less likely than fee-for-service patients to use lowmortality hospitals for coronary artery bypass surgery, which suggests that managed care organizations did not emphasize quality in hospital contracting. Rather, the findings for New York raise the possibility that competition on "true" quality of care was a component of the medical arms race model of hospital competition that prevailed in New York prior to the rapid growth of managed care. Notably, studies have found that patients with fee-for-service insurance are more likely to use hospitals with low mortality than hospitals with high mortality, other things equal (e.g., Luft et al. 1989; Escarce et al. 1999), which gives hospitals a reason to 
compete on quality even when individual patients and their physicians, and not managed care organizations, are making the choices.

Additional findings of our study addressed to the effects on quality of hospital ownership, teaching status, and bed size. Several studies have found similar or worse outcomes in public hospitals compared with private hospitals (e.g., Shapiro et al. 1994; Kuhn et al. 1994). Therefore, the finding of lower mortality for congestive heart failure in diabetes in public hospitals in California was unexpected. To investigate this finding, we compared the characteristics of patients admitted to public and private hospitals in California. We found that compared with patients admitted to private hospitals, those admitted to public hospitals were much younger, had fewer co-morbidities, and had substantially lower predicted probabilities of death for all the study conditions. If our severity measures failed to capture all the differences in illness severity between public and private hospital patients, the finding of lower mortality for congestive heart failure and diabetes in public hospitals could reflect unobserved differences in severity.

The finding that major teaching hospitals in California had higher mortality for three conditions was also unexpected. Several studies have reported better quality of care and lower mortality in major teaching hospitals compared with other hospitals (e.g., Keeler et al. 1992; Rosenthal et al. 1997; Ayanian and Weissman 2002). On the other hand, reports developed by California's Office of Statewide Health Planning and Development (OSHPD) on hospital quality of care for myocardial infarction and pneumonia in California are not consistent with published studies. For myocardial infarction, major teaching hospitals in California were more likely than other hospitals in metropolitan areas to be both low-mortality and high-mortality outliers (OSHPD 2002). For pneumonia, major teaching hospitals were less likely than other hospitals to 
be low-mortality outliers but more likely to be high-mortality outliers (OSHPD 2004). Our findings regarding teaching status and 30-day mortality in New York and Wisconsin were consistent with the published literature.

A noteworthy strength of our study is that we employed linked hospital discharge and vital statistics data, which enabled us to use 30-day mortality, rather than in-hospital mortality, as the measure of quality of care for all patients. Previous studies that used mortality within a fixed time interval after hospital admission as the quality measure were limited to Medicare patients (e.g., Kessler and McClellan 2000; Mukamel, Zwanziger, and Tomaszewski 2001; Shen 2003). Using in-hospital mortality to assess quality may lead to biased estimates of the effects of market structure on quality because market structure may affect hospital length of stay and, consequently, the likelihood of dying in the hospital (e.g., Baker et al. 2002). An additional strength is that we examined mortality for six medical conditions that vary in the degree of professional consensus regarding the need for hospitalization, including several for which there is a great deal of consensus. Further, our focus on a small number of conditions enabled us to include a variety of carefully selected, condition-specific severity measures in our regression models.

Our study also has several limitations. First, discharge data are inherently limited in their ability to capture patient severity, since they lack clinical detail such as laboratory and physiologic data (e.g., Pine et al. 1997). Although we used multiple and detailed conditionspecific measures to assess severity, we cannot rule out the possibility that the limitations of discharge data influenced our findings.

Second, radius-based measures of hospital competition have been criticized because all hospitals inside the radius count equally whereas hospitals just outside the radius do not count at 
all. We addressed this concern by using competition measures based on two different radii-the 75 percent and 90 percent radii-which in practice led to sizable differences in the number of hospitals that contributed to the competition measures. Our results did not change appreciably based on the choice of radius. Radius-based competition measures have also been criticized for being endogenous, but we addressed this concern by using predicted, rather than observed, radii.

Third, the small number of metropolitan areas in each study state precludes drawing definitive conclusions about the impact of HMO penetration on hospital quality of care. Nonetheless, the divergence in the findings for penetration across the three states lends support to the notion that the effect of managed care on quality may vary geographically, possibly depending on characteristics of the managed care market. The results for New York, in particular, call for additional research into the circumstances where managed care may lead to lower hospital quality. In addition, our study did not address the influence of hospital market structure on quality in nonmetropolitan areas.

Fourth, because our study did not assess the impact of hospital competition on costs, the implications of our findings for the welfare effects of competition are uncertain. In particular, we don't know whether competition reduces hospital costs in a state with few competition hospitals, such as Wisconsin, to the same degree as in California.

To conclude, this study provides robust evidence that hospital competition can lead to higher quality of care for a range of medical conditions, at least in states like California and New York where hospitals typically compete with many other hospitals. However, the findings of the study also suggest that quality competition among hospitals may not require the presence of managed care. In particular, the results for New York raise the possibility that quality competition may be a feature of competitive hospital markets irrespective of the characteristics 
of managed care markets. The study findings also suggest that the influence of managed care on hospital quality may vary across states. Taken together, our results underscore the need to consider state-specific effects in studies of health care markets and quality of care. Given the "backlash" against managed care, studies to assess the conditions under which hospitals compete on quality even in the absence of mature managed care markets warrant particular attention. 


\section{REFERENCES}

Ayanian, J.Z., and J.S. Weissman. 2002. "Teaching Hospitals and Quality of Care: A Review of the Literature." The Milbank Quarterly 80 (3): 569-93.

Baker, D.W., D. Einstadter, C.L. Thomas, S.S. Husak, N.H. Gordon, and R.D. Cebul. 2002. "Mortality Trends During a Program that Publicly Reported Hospital Performance." Medical Care 40 (10): 879-90.

Baker, L.C., and C.S. Phibbs. 2002. "Managed Care, Technology Adoption, and Health Care: The Adoption of Neonatal Intensive Care.” The RAND Journal of Economics 33 (3): 524-48.

Bundorf, M.K., K.A. Schulman, J.A. Stafford, D. Gaskin, J.G. Jollis, and J.J. Escarce. 2004.

"Impact of Managed Care on the Treatment, Costs, and Outcomes of Fee-for-Service Medicare Patients with Acute Myocardial Infarction.” Health Services Research 39 (1): 131-52.

Chassin, M.R., R.H. Brook, R.E. Park, J. Keesey, A. Fink, J. Kosecoff, K. Kahn, N. Merrick, and D.H. Solomon. 1986. "Variations in the Use of Medical and Surgical Services by the Medicare Population." New England Journal of Medicine 314 (5): 285-90.

Elixhauser, A., C. Steiner, D.R. Harris, and R.M. Coffey. 1998. “Comorbidity Measures for Use with Administrative Data." Medical Care 36 (1): 8-27. 
Erickson, L.C., D.F. Torchiana, E.C. Schneider, J.W. Newburger, and E.L. Hannan. 2000. "The Relationship between Managed Care Insurance and Use of Lower-Mortality Hospitals for CABG Surgery." Journal of the American Medical Association 283 (15): 1976-82.

Escarce, J.J., R.L. Van Horn, M.V. Pauly, S.V. Williams, J.A. Shea, and W. Chen. 1999. "Health Maintenance Organizations and Hospital Quality for Coronary Artery Bypass Surgery." Medical Care Research and Review 56 (3): 340-62.

Feldman, R., H.C. Chan, J. Kralewski, B. Dowd, and J. Shapiro. 1990. "Effects of HMOs on the Creation of Competitive Markets for Hospital Services." Journal of Health Economics 9 (2): $207-22$.

Gaskin, D.J., and J. Hadley. 1997. "The Impact of HMO Penetration on the Rate of Hospital Cost Inflation, 1985-1993." Inquiry 34 (3): 205-16.

Gaskin, D.J., J.J. Escarce, K. Schulman, and J. Hadley. 2002. “The Determinants of HMOs' Contracting with Hospitals for Bypass Surgery." Health Services Research 37 (4): 963-84.

Gittelsohn, A., and N.R. Powe. 1995. "Small Area Variations in Health Care Delivery in Maryland." Health Services Research 30 (2): 295-317.

Gowrisankaran, G., and R.J. Town. 2003. "Competition, Payers and Hospital Quality." Health Services Research 38 (6, part 1): 1403-21. 
Gresenz, C.R., J. Rogowski, and J.J. Escarce. 2004. “Updated Variable-Radius Measures of Hospital Competition.” Health Services Research 39 (2): 417-30.

Hadley, J. 2003. "Sicker and Poorer—-the Consequences of Being Uninsured: A Review of the Research on the Relationship Between Health Insurance, Medical Care Use, Health, Work, and Income." Medical Care Research and Review 60 (2) Suppl: 3S-75S.

Hannan, E.L., H. Kilburn Jr., M.L. Lindsey, and R. Lewis. 1992. “Clinical Versus Administrative Data Bases for CABG Surgery. Does it Matter?" Medical Care 30 (10): 892907.

Heidenreich, P.A., M. McClellan, C. Frances, and L.C. Baker. 2002. “The Relation between Managed Care Market Share and the Treatment of Elderly Fee-for-Service Patients with Myocardial Infarction.” The American Journal of Medicine 112 (3): 176-82.

Iezzoni, L.I., T. Heeren, S.M. Foley, J. Daley, J. Hughes, and G.A. Coffman. 1994. “Chronic Conditions and Risk of In-Hospital Death.” Health Services Research 29 (4): 435-60.

Iezzoni, L.I., S.M. Foley, J. Daley, J. Hughes, E.S. Fisher, and T. Heeren. 1992. "Comorbidities, Complications, and Coding Bias. Does the Number of Diagnosis Codes Matter in Predicting In-Hospital Mortality?" The Journal of the American Medical Association 267 (16): 2197-203. 
Joskow, P.L. 1980. "The Effects of Competition and Regulation on Hospital Bed Supply and the Reservation Quality of the Hospital." The Bell Journal of Economics 11 (2): 421-47.

Keeler, E.B., L.V. Rubenstein, K.L. Kahn, D. Draper, E.R. Harrison, M.J. McGinty, W.H.

Rogers, and R.H. Brook. 1992. "Hospital Characteristics and Quality of Care." The Journal of the American Medical Association 268 (13): 1709-14.

Keeler, E.B., G. Melnick, and J. Zwanziger. 1999. “The Changing Effects of Competition on Non-Profit and For-Profit Hospital Pricing Behavior." Journal of Health Economics 18 (1): 6986.

Kessler, D.P., and M.B. McClellan. 2000. "Is Hospital Competition Socially Wasteful?" The Quarterly Journal of Economics 115 (4): 577-615.

Kuhn, E.M., A.J. Hartz, H. Krakauer, R.C. Bailey, A.A. Rimm. 1994. "The Relationship of Hospital Ownership and Teaching Status to 30- and 180-Day Adjusted Mortality Rates.” Medical Care 32 (11): 1098-108.

McDonough, J.E. 1997. "Tracking The Demise of State Hospital Rate Setting." Health Affairs 16 (1): 142-49. 
McMahon Jr., L.F., R.A. Wolfe, P.J. Tedeschi. 1989. "Variation in Hospital Admissions among Small Areas. A Comparison of Maine and Michigan.” Medical Care 27 (6): 623-31.

Melnick, G.A., J. Zwanziger, A. Bamezai, and R. Pattison. 1992. “The Effects of Market Structure and Bargaining Position on Hospital Prices.” Journal of Health Economics 11 (3): $217-33$.

Mukamel, D.B., J. Zwanziger, and K.J. Tomaszewski. 2001. "HMO Penetration, Competition, and Risk-Adjusted Hospital Mortality.” Health Services Research 36 (6 part 1): 1019-35.

OSHPD Hospital Outcomes Center. 2004. Report on Hospital Outcomes for CommunityAcquired Pneumonia in California, 1999-2001. Sacramento, California: Healthcare Quality and Analysis Division, California Office of Statewide Health Planning and Development. February.

OSHPD Healthcare Quality and Analysis Division. 2002. Report on Heart Attack Outcomes in California 1996-1998, Volume 1: User's Guide. Sacramento, CA: California Office of Statewide Health Planning and Development. February.

Parkerson, G.R. Jr., W.E. Hammond, J.L. Michener, K.S. Yarnall, and J.L. Johnson. 2005.

"Risk Classification of Adult Primary Care Patients by Self-Reported Quality of Life." Medical Care 43 (2): 189-93. 
Pine, M., M. Noriusis, B. Jones, and G.E. Rosenthal. 1997. "Predictions of Hospital Mortality

Rates: A Comparison of Data Sources.” Annals of Internal Medicine 126 (5): 347-54.

Rainwater, J.A., and P.S. Romano. 2003. "What Data do California HMOs Use to Select Hospitals for Contracting?" The American Journal of Managed Care 9 (8): 553-61.

Romano, P.S., and D.H. Mark. 1994. "Bias in the Coding of Hospital Discharge Data and Its Implications for Quality Assessment.” Medical Care 32 (1): 81-90.

Romano, P.S. and R. Mutter. 2004. “The Evolving Science of Quality Measurement for Hospitals: Implications for Studies of Competition and Consolidation.” International Journal of Health Care Finance and Economics 4 (2): 131-57.

Robinson, J.C. 1991. "HMO Market Penetration and Hospital Cost Inflation in California." The Journal of the American Medical Association 266 (19) 2719-23.

Robinson, J. C., and H. S. Luft. 1985. “The Impact of Hospital Market Structure on Patient Volume, Average Length of Stay, and the Cost of Care.” Journal of Health Economics 4 (4): 333-56.

Rosenthal, G.E., D.L. Harper, L.M. Quinn, and G.S. Cooper. 1997. “Severity-Adjusted Mortality and Length of Stay in Teaching and Nonteaching Hospitals. Results of a Regional Study." The Journal of the American Medical Association 278 (6): 485-90. 
Salit, S., S. Fass, and M. Nowak. 2002. "Out of the Frying Pan: New York City Hospitals in an Age of Deregulation." Health Affairs 21 (1): 127-39.

Sari, N. 2002. “Do Competition and Managed Care Improve Quality?” Health Economics 11 (7): 571-84.

Schulman, K.A., L.E. Rubenstein, D.M. Seils, M. Harris, J. Hadley, and J.J. Escarce. 1997. "Quality Assessment in Contracting for Tertiary Care Services by HMOs: A Case Study of Three Markets.” The Joint Commission Journal on Quality Improvement 23 (2): 117-27.

Shapiro, M.F., R.E. Park, J. Keesey, and R.H. Brook. 1994. "The Effect of Alternative CaseMix Adjustments on Mortality Differences Between Municipal and Voluntary Hospitals in New York City." Health Services Research 29 (1): 95-112.

Shen, Y.C. 2003. "The Effect of Financial Pressure on the Quality of Care in Hospitals." Journal of Health Economics 22 (2): 243-69.

Shortell, S.M., and E.F. Hughes. 1988. The Effects of Regulation, Competition, and Ownership on Mortality Rates among Hospital Inpatients. The New England Journal of Medicine 318 (17): 1100-7. 
Wennberg, J.E., K. McPherson, and P. Caper. 1984. "Will Payment Based on Diagnosis-

Related Groups Control Hospital Costs?" The New England Journal of Medicine 311 (5): 295300.

Wennberg, J.E. 1987. "Population Illness Rates Do Not Explain Population Hospitalization Rates. A Comment on Mark Blumberg's Thesis that Morbidity Adjusters are Needed to Interpret Small Area Variations.” Medical Care 25 (4): 354-9.

Young, G.J., J.F. Burgess Jr., and D. Valley. 2002. “Competition among Hospitals for HMO Business: Effect of Price and Nonprice Attributes." Health Services Research 37 (5): 1267-89.

Zhang, M.B., and K.F. Yu. 1998. "What's the Relative Risk? A Method for Correcting the Odds Ratio in Cohort Studies of Common Outcomes. Journal of the American Medical Association 280(19): 1690-1691.

Zwanziger, J., and G.A. Melnick. 1988. "The Effects of Hospital Competition and the Medicare PPS Program on Hospital Cost Behavior in California.” Journal of Health Economics 7 (4): $301-20$. 


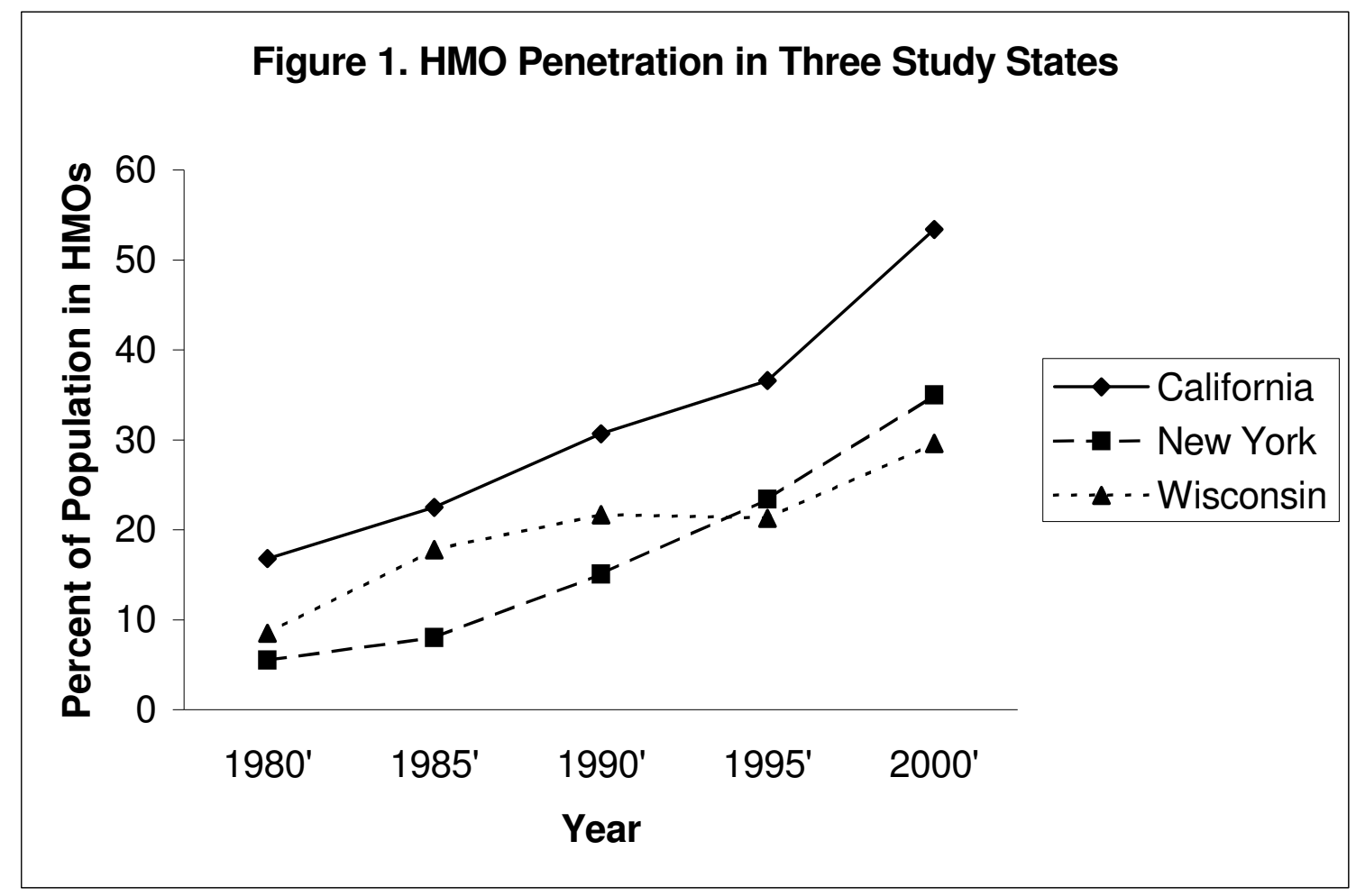


Table 1: Thirty-Day Mortality for Study Conditions, By State.

\begin{tabular}{|l|c|c|c|c|c|c|}
\hline & AMI & HIP & CVA & GIH & CHF & DM \\
\hline $\begin{array}{l}\text { California } \\
\text { 30-day Mortality }\end{array}$ & $13.2 \%$ & $6.3 \%$ & $16.0 \%$ & $5.7 \%$ & $8.5 \%$ & $3.3 \%$ \\
N & 227,446 & 129,944 & 237,248 & 216,443 & 355,613 & 154,837 \\
& & & & & & \\
New York & & & & & \\
$\quad$ 30-day Mortality & $12.5 \%$ & $5.7 \%$ & $15.3 \%$ & $5.8 \%$ & $8.0 \%$ & $2.8 \%$ \\
N & 153,970 & 75,567 & 134,016 & 121,733 & 262,844 & 128,574 \\
& & & & & & \\
Wisconsin & & & & & \\
30-day Mortality & $13.3 \%$ & $7.2 \%$ & $17.1 \%$ & $6.0 \%$ & $10.8 \%$ & $3.3 \%$ \\
N & 37,693 & 21,810 & 34,037 & 29,011 & 55,475 & 22,846 \\
\hline
\end{tabular}


Table 2: Descriptive Data: Hospital Competition, HMO Penetration, and Other Hospital Characteristics in Three States

\begin{tabular}{|c|l|l|l|}
\hline & \multicolumn{3}{|c|}{ Percentage or Mean (SD) } \\
\hline & California & New York & Wisconsin \\
\hline Hospital Competition & & & \\
\hline $90 \%$ Radius Measures & & & \\
\hline 1 - Herfindahl Index & $0.79(0.25)$ & $0.72(0.31)$ & $0.68(0.29)$ \\
\hline Number of Hospitals & $19.8(25.6)$ & $28.0(44.4)$ & $8.0(7.7)$ \\
\hline $75 \%$ Radius Measures & & & \\
\hline 1- Herfindahl & $0.61(0.33)$ & $0.57(0.37)$ & $0.51(0.30)$ \\
\hline Number of Hospitals & $7.3(11.1)$ & $12.4(22.7)$ & $3.3(4.0)$ \\
\hline & & & \\
\hline HMO Penetration & $0.43(0.13)$ & $0.34(0.14)$ & $0.32(0.13)$ \\
\hline & & & \\
\hline Hospital Characteristics & & & \\
\hline Hospital Ownership & & & \\
\hline Nonprofit & $67.1 \%$ & $84.9 \%$ & $98.5 \%$ \\
\hline Public & $5.9 \%$ & $9.7 \%$ & $1.5 \%$ \\
\hline For profit & $27.0 \%$ & $5.4 \%$ & --- \\
\hline Teaching Status & & & \\
\hline No & $70.3 \%$ & $46.6 \%$ & $52.5 \%$ \\
\hline Minor & $22.1 \%$ & $24.9 \%$ & $42.2 \%$ \\
\hline Major & $7.6 \%$ & $28.5 \%$ & $5.3 \%$ \\
\hline Hospital Bed Size & & & \\
\hline$<100$ beds & $25.5 \%$ & $11.7 \%$ & $32.8 \%$ \\
\hline 100-199 beds & $36.0 \%$ & $22.3 \%$ & $30.8 \%$ \\
\hline 200-399 beds & $32.1 \%$ & $34.3 \%$ & $28.5 \%$ \\
\hline 400+ beds & $6.4 \%$ & $31.7 \%$ & $7.9 \%$ \\
\hline & & & \\
\hline
\end{tabular}


Table 3a: Regression Results: Effects of Hospital Competition, HMO Penetration, and Hospital Characteristics on 30-Day Mortality for Six Medical Conditions in California.

\begin{tabular}{|c|c|c|c|c|c|c|}
\hline & AMI & HIP & CVA & GIH & CHF & DM \\
\hline Explanatory Variable & $\begin{array}{l}\text { Relative } \\
\text { Risk }\end{array}$ & $\begin{array}{l}\text { Relative } \\
\text { Risk }\end{array}$ & $\begin{array}{l}\text { Relative } \\
\text { Risk }\end{array}$ & $\begin{array}{l}\text { Relative } \\
\text { Risk }\end{array}$ & $\begin{array}{l}\text { Relative } \\
\text { Risk }\end{array}$ & $\begin{array}{c}\text { Relative } \\
\text { Risk }\end{array}$ \\
\hline $\begin{array}{l}\text { Hospital Competition } \\
\text { (1-Herfindahl, } 90 \% \text { radius) }\end{array}$ & 0.93 & $0.75 * * *$ & $0.71 * * *$ & $0.83 * *$ & $0.88 *$ & $0.82 *$ \\
\hline HMO Penetration & 0.91 & 0.87 & 0.98 & $0.76^{* *}$ & $0.78 * * *$ & 0.93 \\
\hline \multicolumn{7}{|l|}{ Hospital Ownership } \\
\hline Non-Profit (excluded) & 1.00 & 1.00 & 1.00 & 1.00 & 1.00 & 1.00 \\
\hline Public & $1.35 * * *$ & 0.98 & 1.06 & 1.08 & $0.87 *$ & $0.70 * * *$ \\
\hline For Profit & $1.08^{* * *}$ & 1.05 & $0.92 * *$ & 0.98 & $0.93 * *$ & $0.85 * * *$ \\
\hline \multicolumn{7}{|l|}{ Teaching Status } \\
\hline No (excluded) & 1.00 & 1.00 & 1.00 & 1.00 & 1.00 & 1.00 \\
\hline Minor & 0.99 & $1.07 *$ & 1.04 & 0.99 & 1.01 & $1.10^{*}$ \\
\hline Major & 0.93 & 1.05 & $1.12 * *$ & $1.19 * * *$ & 0.96 & $1.15^{*}$ \\
\hline \multicolumn{7}{|l|}{ Hospital Bed Size } \\
\hline$<100$ Beds (excluded) & 1.00 & 1.00 & 1.00 & 1.00 & 1.00 & 1.00 \\
\hline 100-199 Beds & 0.97 & 1.01 & 0.98 & 1.05 & 1.03 & 0.99 \\
\hline 200-399 Beds & $0.94 *$ & 1.02 & $0.92 *$ & 1.05 & 1.00 & 0.91 \\
\hline $400+$ Beds & $0.90 * *$ & 0.94 & $0.89 *$ & 0.94 & $0.85 * * *$ & $0.72 * * *$ \\
\hline
\end{tabular}

Notes: Statistical significance is indicated as follows: ${ }^{*} \mathrm{p}<0.10,{ }^{* *} \mathrm{p}<0.05,{ }^{* * *} \mathrm{p}<0.01$. The regression models included patient severity measures and year indicators. 
Table 3b: Regression Results: Effects of Hospital Competition, HMO Penetration, and Hospital Characteristics on 30-Day Mortality for Six Medical Conditions in New York.

\begin{tabular}{|c|l|l|l|l|l|l|}
\hline & \multicolumn{1}{|c|}{ AMI } & \multicolumn{1}{|c|}{ HIP } & \multicolumn{1}{|c|}{ CVA } & \multicolumn{1}{|c|}{ GIH } & \multicolumn{1}{c|}{ CHF } & DM \\
\hline Explanatory Variable & $\begin{array}{c}\text { Relative } \\
\text { Risk }\end{array}$ & $\begin{array}{c}\text { Relative } \\
\text { Risk }\end{array}$ & $\begin{array}{c}\text { Relative } \\
\text { Risk }\end{array}$ & $\begin{array}{c}\text { Relative } \\
\text { Risk }\end{array}$ & $\begin{array}{c}\text { Relative } \\
\text { Risk }\end{array}$ & $\begin{array}{c}\text { Relative } \\
\text { Risk }\end{array}$ \\
\hline $\begin{array}{l}\text { Hospital Competition } \\
\text { (1-Herfindahl, 90\% radius) }\end{array}$ & $0.85^{* * *}$ & 0.91 & 0.92 & $0.86^{*}$ & 0.94 & $0.86^{*}$ \\
\hline HMO Penetration & 1.20 & $1.54^{* * *}$ & $1.33^{* * *}$ & $1.54^{* * *}$ & $1.43^{* * *}$ & 1.13 \\
\hline Hospital Ownership & & & & & & \\
\hline Non-Profit (excluded) & 1.00 & 1.00 & 1.00 & 1.00 & 1.00 & 1.00 \\
\hline Public & 1.03 & 1.00 & $1.36^{* * *}$ & 1.13 & 0.95 & 0.97 \\
\hline For Profit & 0.98 & $0.61^{* * *}$ & $0.90^{*}$ & 0.88 & 0.94 & 0.90 \\
\hline Teaching Status & & & & & & \\
\hline No (excluded) & 1.00 & 1.00 & 1.00 & 1.00 & 1.00 & 1.00 \\
\hline Minor & 1.03 & 0.98 & 1.03 & 1.00 & 0.99 & 1.03 \\
\hline Major & 0.98 & 0.91 & $0.89 * *$ & 0.98 & $0.82^{* * *}$ & $0.81^{* *}$ \\
\hline Hospital Bed Size & & & & & & \\
\hline$<100$ Beds (excluded) & 1.00 & 1.00 & 1.00 & 1.00 & 1.00 & 1.00 \\
\hline 100-199 Beds & 0.98 & 0.94 & 1.01 & 1.06 & 1.05 & 0.95 \\
\hline 200-399 Beds & 1.02 & 0.99 & 0.94 & 1.14 & 1.09 & 0.97 \\
\hline 400+ Beds & 1.06 & 0.93 & 0.99 & $1.20^{*}$ & $1.12^{*}$ & 1.08 \\
\hline
\end{tabular}

Notes: Statistical significance is indicated as follows: ${ }^{*} \mathrm{p}<0.10,{ }^{*} \mathrm{p}<0.05,{ }^{*} * \mathrm{p}<0.01$.

The regression models included patient severity measures and year indicators. 
Table 3c: Regression Results: Effects of Hospital Competition, HMO Penetration, and Hospital Characteristics on 30-Day Mortality for Six Medical Conditions in Wisconsin.

\begin{tabular}{|c|l|l|l|l|l|l|}
\hline & \multicolumn{1}{|c|}{ AMI } & \multicolumn{1}{|c|}{ HIP } & \multicolumn{1}{|c|}{ CVA } & \multicolumn{1}{|c|}{ GIH } & \multicolumn{1}{c|}{ CHF } & DM \\
\hline Explanatory Variable & $\begin{array}{c}\text { Relative } \\
\text { Risk }\end{array}$ & $\begin{array}{c}\text { Relative } \\
\text { Risk }\end{array}$ & $\begin{array}{c}\text { Relative } \\
\text { Risk }\end{array}$ & $\begin{array}{c}\text { Relative } \\
\text { Risk }\end{array}$ & $\begin{array}{c}\text { Relative } \\
\text { Risk }\end{array}$ & $\begin{array}{c}\text { Relative } \\
\text { Risk }\end{array}$ \\
\hline $\begin{array}{c}\text { Hospital Competition } \\
\text { (1-Herfindahl, 90\% radius) }\end{array}$ & 1.06 & 0.98 & 0.90 & 0.94 & 1.12 & 1.02 \\
\hline HMO Penetration & 0.78 & 1.03 & 0.95 & 0.78 & $0.66^{* * *}$ & 0.76 \\
\hline Teaching Status & & & & & & \\
\hline No (excluded) & 1.00 & 1.00 & 1.00 & 1.00 & 1.00 & 1.00 \\
\hline Minor & 0.95 & 0.98 & 1.04 & 0.98 & $1.10^{*}$ & 0.95 \\
\hline Major & $1.20^{*}$ & 1.03 & 1.07 & 0.95 & $0.87^{*}$ & $0.55^{* *}$ \\
\hline Hospital Bed Size & & & & & & \\
\hline$<100$ Beds (excluded) & 1.00 & 1.00 & 1.00 & 1.00 & 1.00 & 1.00 \\
\hline 100-199 Beds & 1.15 & 0.94 & 0.91 & $1.18^{*}$ & 0.90 & 0.99 \\
\hline 200-399 Beds & $1.20^{*}$ & 0.93 & $0.85^{* *}$ & 1.15 & $0.83^{* *}$ & 0.91 \\
\hline 400+ Beds & $1.27^{* *}$ & 0.86 & $0.85^{* *}$ & $1.24^{*}$ & $0.84^{*}$ & 0.85 \\
\hline
\end{tabular}

Notes: Statistical significance is indicated as follows: $* \mathrm{p}<0.10, * * \mathrm{p}<0.05, * * * \mathrm{p}<0.01$. The regression models included patient severity measures and year indicators. However, the models for Wisconsin did not include hospital ownership. 
Table 4: Regression Results: Effects of Hospital Competition Using Alternate Measures of Competition, By State.

\begin{tabular}{|c|c|c|c|c|c|c|}
\hline & AMI & HIP & CVA & GIH & CHF & DM \\
\hline $\begin{array}{l}\text { State/ } \\
\text { Competition Measure }\end{array}$ & $\begin{array}{l}\text { Relative } \\
\text { Risk }\end{array}$ & $\begin{array}{c}\text { Relative } \\
\text { Risk }\end{array}$ & $\begin{array}{l}\text { Relative } \\
\text { Risk }\end{array}$ & $\begin{array}{l}\text { Relative } \\
\text { Risk }\end{array}$ & $\begin{array}{l}\text { Relative } \\
\text { Risk }\end{array}$ & $\begin{array}{c}\text { Relative } \\
\text { Risk }\end{array}$ \\
\hline \multicolumn{7}{|l|}{ California } \\
\hline \multicolumn{7}{|l|}{ 90\% Radius Measures } \\
\hline 1-Herfindahl Index & 0.93 & $0.75 * * *$ & $0.71 * * *$ & $0.83 * *$ & $0.88 *$ & $0.82 *$ \\
\hline Number of Hospitals & 0.99 & $0.97 * * *$ & $0.96 * * *$ & $0.98 * * *$ & $0.96 * * *$ & $0.97 * * *$ \\
\hline \multicolumn{7}{|l|}{$75 \%$ Radius Measures } \\
\hline 1-Herfindahl Index & 1.02 & $0.87 * *$ & $0.77 * * *$ & 0.94 & $0.89 * *$ & 0.92 \\
\hline Number of Hospitals & 0.99 & $0.95 * * *$ & $0.93 * * *$ & $0.97 * * *$ & $0.94 * * *$ & $0.96 * * *$ \\
\hline \multicolumn{7}{|l|}{ New York } \\
\hline \multicolumn{7}{|l|}{ 90\% Radius Measures } \\
\hline 1-Herfindahl Index & $0.85 * * *$ & 0.91 & 0.92 & $0.86^{*}$ & 0.94 & $0.86^{*}$ \\
\hline Number of Hospitals & $0.97 * * *$ & $0.99 *$ & $0.97 * * *$ & $0.97 * * *$ & 1.00 & 1.00 \\
\hline \multicolumn{7}{|l|}{$75 \%$ Radius Measures } \\
\hline 1-Herfindahl Index & $0.90 *$ & 0.92 & 0.94 & $0.87 * *$ & $0.89 * *$ & $0.83 * *$ \\
\hline Number of Hospitals & $0.96 * * *$ & $0.97 * * *$ & $0.97 * * *$ & $0.95 * * *$ & 0.99 & 0.98 \\
\hline \multicolumn{7}{|l|}{ Wisconsin } \\
\hline \multicolumn{7}{|l|}{ 90\% Radius Measures } \\
\hline 1-Herfindahl Index & 1.06 & 0.98 & 0.90 & 0.94 & 1.12 & 1.02 \\
\hline Number of Hospitals & 1.01 & 1.01 & 0.99 & 0.95 & 0.98 & 0.97 \\
\hline \multicolumn{7}{|l|}{$75 \%$ Radius Measures } \\
\hline 1-Herfindahl Index & 1.11 & 1.17 & 0.94 & 1.10 & 0.96 & 1.01 \\
\hline Number of Hospitals & 1.04 & 1.04 & 1.00 & 1.02 & $0.96^{*}$ & 1.00 \\
\hline
\end{tabular}

Notes: Statistical significance is indicated as follows: $* \mathrm{p}<0.10, * * \mathrm{p}<0.05, * * * \mathrm{p}<0.01$. The regression models included HMO penetration, hospital ownership (except in Wisconsin), teaching status, bed size, patient severity measures, and year indicators. 
Table 5: Regression Results: Effects of Hospital Competition and HMO Penetration 90Day and 180-Day Mortality for Six Medical Conditions, By State.

\begin{tabular}{|c|c|c|c|c|c|c|}
\hline & AMI & HIP & CVA & GIH & CHF & DM \\
\hline $\begin{array}{l}\text { State/Outcome/ } \\
\text { Competition Measure }\end{array}$ & $\begin{array}{l}\text { Relative } \\
\text { Risk }\end{array}$ & $\begin{array}{c}\text { Relative } \\
\text { Risk }\end{array}$ & $\begin{array}{c}\text { Relative } \\
\text { Risk }\end{array}$ & $\begin{array}{c}\text { Relative } \\
\text { Risk }\end{array}$ & $\begin{array}{c}\text { Relative } \\
\text { Risk }\end{array}$ & $\begin{array}{c}\text { Relative } \\
\text { Risk }\end{array}$ \\
\hline \multicolumn{7}{|l|}{ California } \\
\hline \multicolumn{7}{|l|}{ 90-Day Mortality } \\
\hline $\begin{array}{l}\text { Hospital Competition } \\
\text { (1-Herfindahl, 90\% radius) }\end{array}$ & 0.93 & $0.84 * *$ & $0.75^{* * *}$ & $0.89^{*}$ & $0.90^{*}$ & $0.84 *$ \\
\hline HMO Penetration & 0.92 & 0.93 & 1.01 & $0.83 * *$ & $0.81 * * *$ & 1.00 \\
\hline \multicolumn{7}{|l|}{ 180-Day Mortality } \\
\hline $\begin{array}{l}\text { Hospital Competition } \\
\text { (1-Herfindahl, 90\% radius) }\end{array}$ & 0.95 & $0.87 * *$ & $0.77^{* * *}$ & 0.93 & 0.94 & 0.91 \\
\hline HMO Penetration & 0.91 & 0.91 & 1.03 & $0.80^{* * *}$ & $0.85^{* * * *}$ & 1.03 \\
\hline \multicolumn{7}{|l|}{ New York } \\
\hline \multicolumn{7}{|l|}{ 90-Day Mortality } \\
\hline $\begin{array}{l}\text { Hospital Competition } \\
\text { (1-Herfindahl, 90\% radius) }\end{array}$ & $0.83^{* * * *}$ & $0.89^{*}$ & $0.90^{*}$ & $0.82 * *$ & 0.93 & 0.91 \\
\hline HMO Penetration & $1.27 * *$ & $1.47^{* * * *}$ & $1.21 * *$ & $1.36^{* *}$ & $1.42 * * *$ & $1.42 *$ \\
\hline \multicolumn{7}{|l|}{ 180-Day Mortality } \\
\hline $\begin{array}{l}\text { Hospital Competition } \\
\text { (1-Herfindahl, 90\% radius) }\end{array}$ & $0.86^{* * * *}$ & $0.89^{* *}$ & $0.91^{*}$ & $0.85^{* * *}$ & 0.96 & 0.90 \\
\hline HMO Penetration & 1.29 *** & $1.43^{* * *}$ & $1.18^{* *}$ & $1.24 *$ & $1.38^{* * *}$ & $1.39 * *$ \\
\hline \multicolumn{7}{|l|}{ Wisconsin } \\
\hline \multicolumn{7}{|l|}{ 90-Day Mortality } \\
\hline $\begin{array}{l}\text { Hospital Competition } \\
\text { (1-Herfindahl, 90\% radius) }\end{array}$ & 1.09 & 1.03 & 0.95 & 1.00 & 1.07 & 0.90 \\
\hline HMO Penetration & 0.72 & 0.93 & 0.95 & 0.81 & 0.80 & 0.63 \\
\hline \multicolumn{7}{|l|}{ 180-Day Mortality } \\
\hline $\begin{array}{l}\text { Hospital Competition } \\
\text { (1-Herfindahl, 90\% radius) }\end{array}$ & 1.09 & 1.03 & 0.98 & 0.97 & 1.07 & 1.07 \\
\hline HMO Penetration & $0.65^{*}$ & 0.99 & 0.96 & 0.77 & $0.78^{*}$ & 0.66 \\
\hline
\end{tabular}

Notes: Statistical significance is indicated as follows: $* \mathrm{p}<0.10, * * \mathrm{p}<0.05, * * * \mathrm{p}<0.01$. The regression models included hospital ownership (except in Wisconsin), teaching status, bed size, patient severity measures, and year indicators. 